\title{
Surface Integrity and Fatigue Behaviour of Electric Discharged Machined and Milled Austenitic Stainless Steel
}

Mattias Lundberg, Jonas Saarimäki, Johan Moverare and Mattias Calmunger

Journal Article

\section{Tweet}

N.B.: When citing this work, cite the original article.

Original Publication:

Mattias Lundberg, Jonas Saarimäki, Johan Moverare and Mattias Calmunger, Surface Integrity and Fatigue Behaviour of Electric Discharged Machined and Milled Austenitic Stainless Steel, Materials Characterization, 2017. 124, pp.215-222.

http://dx.doi.org/10.1016/j.matchar.2017.01.003

Copyright: Elsevier

http://www.elsevier.com/

Postprint available at: Linköping University Electronic Press

http://urn.kb.se/resolve?urn=urn:nbn:se:liu:diva-134043

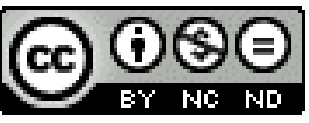

LINKÖPINGS

UNIVERSITET 


\title{
Surface Integrity and Fatigue Behaviour of Electric Discharged Machined and Milled Austenitic Stainless Steel
}

Mattias Lundberga, * , Jonas Saarimäki ${ }^{a}$, Johan J. Moverare ${ }^{a}$, Mattias Calmunger ${ }^{a}$

aDivision of Engineering Materials, Department of Management and Engineering, Linköping University, SE-581 83 Linköping, Sweden

*Corresponding author: mattias.lundberg@liu.se

\begin{abstract}
Machining of austenitic stainless steels can result in different surface integrities and different machining process parameters will have a great impact on the component fatigue life. Understanding how machining processes affect the cyclic behaviour and microstructure are of outmost importance in order to improve existing and new life estimation models. Milling and electrical discharge machining (EDM) have been used to manufacture rectangular four-point bend fatigue test samples; subjected to high cycle fatigue. Before fatigue testing, surface integrity characterisation of the two surface conditions was conducted using scanning electron microscopy, surface roughness, residual stress profiles, and hardness profiles. Differences in cyclic behaviour were observed between the two surface conditions by the fatigue testing. The milled samples exhibited a fatigue limit. EDM samples did not show the same behaviour due to ratchetting. Recrystallized nano sized grains were identified at the severely plastically deformed surface of the milled samples. Large amounts of bent mechanical twins were observed $\sim 5 \mu \mathrm{m}$ below the surface. Grain shearing and subsequent grain rotation from milling bent the mechanical twins. EDM samples showed much less plastic deformation at the surface. Surface tensile residual stresses of $\sim 500 \mathrm{MPa}$ and $\sim 200 \mathrm{MPa}$ for the milled and EDM samples respectively were measured.
\end{abstract}




\section{Keywords: Austenitic stainless steel, Fatigue, Surface Integrity, SEM, XRD, Hardness}

\section{Introduction}

Stainless steels are used in various industries such as aerospace, automotive, biomedical, and power generation. Due to its wide field of use, extensive research has been conducted in order to improve the mechanical properties and performance of stainless steels. Manufacturing a component to the required geometrical tolerances without the use of any machining is next too impossible. All types of machining e.g., milling, turning, drilling, plasma machining, laser cutting, water jet cutting, and electrical discharge machining (EDM) results in different surface integrities, resulting in different mechanical behaviour. Optimising machining parameters in order to minimise machining time without compromising surface quality and/or given geometrical tolerances have been investigated in [1]. Different surface conditions can alter the mechanical behaviour during cyclic loading and influence fatigue life of AISI 304 and AISI 316 stainless steels [2-13]. To counteract the possibly detrimental effects that might be induced by machining, post treatments can be used to increase fatigue resistance and component life. A common way to achieve this is to altering the surface integrity by e.g., introducing an increased strain hardened layer, grain fragmentation and/or residual stress (RS) optimisation $[7,14-16]$. Commonly used surface processing techniques in industry today are shot peening, laser shock peening, surface mechanical attrition treatment and deep rolling. Machining and surface treatments can alter mechanical properties such as fatigue strength. Therefore, it is essential to understand the microstructural evolution at the surface and its impact on fatigue resistance [1720]. Four-point bending fatigue testing may be a suitable fatigue testing method to study the surface integrity after machining, since the highest stresses from testing will be concentrated at the sample surface.

This study investigates the effect of milling and EDM on high cycle fatigue of AISI 304 austenitic stainless steel tube material. Fatigue resistance in relation to surface integrity is investigated using the 
scanning electron microscopy (SEM) techniques, electron channelling contrast imaging (ECCI), electron backscatter diffraction (EBSD), and energy dispersion spectroscopy (EDS), and hardness testing, and RS measurements using X-ray diffraction (XRD).

\section{Material and experimental procedure}

The AISI 304 austenitic stainless steel used for this study was provided by Sandvik Materials Technology in Sandviken, Sweden. The tube material was manufactured by hot extrusion cold pilgering and solution annealed at $1060^{\circ} \mathrm{C}$ for 15 minutes. Chemical composition of the steel in weight percentage is C: $0.015, \mathrm{Si}: 0.35, \mathrm{Mn}: 1.2, \mathrm{Cr}: 18.3, \mathrm{Ni}: 10.3, \mathrm{~W}: 0.05, \mathrm{Cu}: 0.3, \mathrm{Nb}: 0.01, \mathrm{~N}: 0.07$, and balance Fe. The mechanical properties were i.e., yield strength, $R_{\mathrm{p} 0.2}=210 \mathrm{MPa}$, tensile strength, $R_{\mathrm{m}}=515 \mathrm{MPa}$, Young's modulus, $E=200 \mathrm{GPa}$.

Ten rectangular shaped samples were extracted from the tube using milling and EDM respectively. Milling was performed with coolant and a Sandvik Model 390 cutting tool with a $\varnothing$ of $16 \mathrm{~mm}$ and new inserts, $0.8 \mathrm{~mm}$ nose radius, rotation speed of $1200 \mathrm{rpm}$ and a feed rate of $200 \mathrm{~mm} / \mathrm{min}$. A schematic sketch of the milling process is shown in Figure 1 (a). EDM was performed using a $\varnothing 0.25 \mathrm{~mm}$ brass wire with a cutting speed of $7.6 \mathrm{~mm} / \mathrm{min}, 50 \mathrm{~V}$, and $4.0 \mathrm{~A}$. Surface roughness, $R_{a}$, measurements were conducted using a Mitutoyo Surftest SJ-201M. Measurements of the milled and the EDM surface had a Ra value of 0.81 and 2.27 respectively.

\subsection{Fatigue testing}

Four-point bending fatigue testing was done in a servo-hydraulic MTS machine using a Instron 8800 control system with a frequency of $15 \mathrm{~Hz}$ and a load ratio of $R=0.1$. The experimental setup is shown in Figure 1 (b). To fulfil the recommendations by Zhai et al. [21], samples measuring $10 \times 10 \times 80 \mathrm{~mm}$, an inner span of $13 \mathrm{~mm}$, and an outer span of $58 \mathrm{~mm}$ for the test setup were used. A drop in displacement of $3.5 \%$ was used as the failure criterion. A test was considered a run-out (RO) if exceeding two million cycles. 

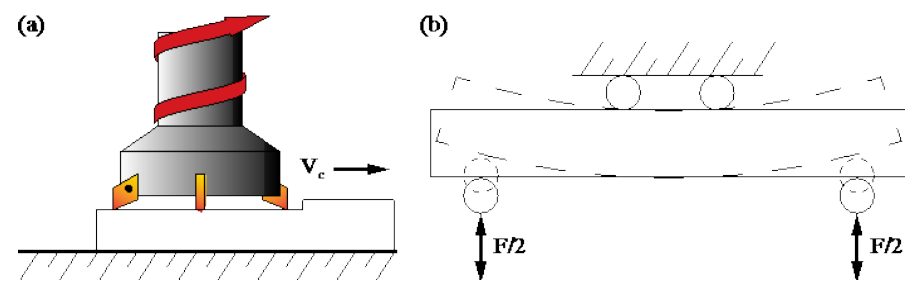

Figure 1: Schematic sketch of the (a) milling process, and (b) four-point bending setup.

\subsection{Hardness testing and X-ray diffraction}

A Struers DuraScan G5, following ISO 6507 and ASTM E384, equipped with a Vickers diamond was used for hardness measurements with an applied load of $0.01 \mathrm{~g}$. For hardness depth profiles 65 and 30 indentations were used for the milled and EDM samples respectively. Bulk hardness was measured using 35 indentations.

X-ray measurements were performed using a four-circle goniometer Seifert X-ray machine, equipped with a linear position sensitive detector and a Cr-tube. RS evaluations were conducted using the $\sin ^{2} \psi$ method [22] with the $\gamma$-Fe $\{220\}$ diffraction peak, at $2 \theta \approx 128.8^{\circ}$. X-ray elastic constants $s_{1}$ and $1 / 2 s_{2}$ were taken from reference [23]. The RS measurements conducted, used nine equally spread $\sin ^{2} \psi$ values with $\psi$-angles between $\pm 55^{\circ}$. Material removal was done using a perchloric acid-base electrolyte in a Struers LetcroPol-5 machine. No corrections were done for material removed.

\subsection{Microscopy}

Samples were prepared by grinding and mechanical polishing using a Struers Tegramin machine with the parameter settings in Table 1. Samples were cleaned using water, soap and cotton after each grinding operation. After each polishing cloth they were cleaned with water, soap and cotton followed by ultrasonic cleaning in ethanol and a final cleaning with water, soap and cotton. A Hitachi SU-70 field emission gun SEM, operating at $10-20 \mathrm{kV}$, was used to study the sample surface integrity and deformation caused by the different cutting procedures. The analytical SEM-techniques used were $\mathrm{ECCl}, \mathrm{EBSD}$, and EDS. 
Table 1: Sample preparation steps.

\begin{tabular}{|c|c|c|c|c|c|}
\hline $\begin{array}{l}\text { Grinding paper or } \\
\text { polishing cloth }\end{array}$ & Grit size $[\mu \mathrm{m}]$ & $\begin{array}{l}\text { Load (each } \\
\text { sample) [N] }\end{array}$ & $\begin{array}{l}\text { Time } \\
\text { [min] }\end{array}$ & $\begin{array}{c}\text { Number } \\
\text { of } \\
\text { papers }\end{array}$ & $\begin{array}{l}\text { Material } \\
\text { removed } \\
{[\mu \mathrm{m}]}\end{array}$ \\
\hline SiC paper 500 & 30 & 40 & 4.00 & 2 & 400 \\
\hline SiC paper 1200 & 15 & 40 & 4.00 & 1 & 60 \\
\hline SiC paper 4000 & 5 & 40 & 4.00 & 3 & 35 \\
\hline Silk cloth & $\begin{array}{c}\text { Diamond } \\
\text { suspension } 3\end{array}$ & 30 & 8.00 & & 10 \\
\hline Woven wool cloth & $\begin{array}{c}\text { Diamond } \\
\text { suspension } 1\end{array}$ & 15 & 10.00 & & 5 \\
\hline $\begin{array}{c}\text { Rayon-viscose fibres } \\
\text { cloth }\end{array}$ & $\begin{array}{c}\text { Diamond } \\
\text { suspension } 0.25\end{array}$ & 15 & 15.00 & & \\
\hline Neoprene foam cloth & $\begin{array}{l}\text { Colloidal silica } \\
\text { suspension } 0.04\end{array}$ & 15 & 5.00 & & \\
\hline Neoprene foam cloth & Water & 15 & 1.00 & & \\
\hline
\end{tabular}

ECCl investigations were performed using a solid state 4-quadrant backscatter electron detector, an acceleration voltage of 10-20 kV, and a working distance of 7-8 mm. Changes in the crystallographic structure gives the speckled pattern observed with ECCI [24-26]. The probability of detecting back scattering electrons varies with the rotational changes around any axis of the crystal. Local misorientation, defects, and strain fields are shown as contrast variations because ECCI uses the interaction between backscattered electrons and the crystal planes to generate contrast. This makes $\mathrm{ECCl}$ is a good technique in order to investigate deformed materials [24-26]. It is not possible to separate or quantify the contributions from elastic and plastic strain when simultaneously present. 
Crystallographic orientation quantification was done using an OXFORD electron backscatter diffraction (EBSD) detector. Sample configuration used: tilted $70^{\circ}$, a working distance of $20 \mathrm{~mm}$, an acceleration voltage of $15 \mathrm{kV}$ and a step size of $0.5 \mu \mathrm{m}$. To evaluate the EBSD measurements the HKL software Channel 5 was used. A mis-orientation (orientation difference between two neighbouring measurement points) between $1.5^{\circ}-10^{\circ}$ defines a LAGB while $>10^{\circ}$ is regarded as a high angle grain boundary. In the EBSD maps LAGB's are represented with black lines, angles between $10^{\circ}-50^{\circ}$ are with red lines, and angles $>50^{\circ}$ with blue lines. Non indexed points (zero solutions) are represented as white dots.

Qualitative chemical composition measurement was done using an OXFORD EDS detector at a working distance of $15 \mathrm{~mm}$ and an acceleration voltage of $20 \mathrm{kV}$.

\section{Results}

All milled samples were run-outs (RO) when tested with a maximum stress of $400,410,420$, and 425 MPa. The two samples run with a maximum stress of $430 \mathrm{MPa}$ failed after 346500 and 776000 cycles respectively. The EDM samples were RO for all tested loads. Fatigue testing results are listed in Table 2.

Table 2: Fatigue testing results for milled and EDM surfaces.

\begin{tabular}{|l|l|l|l|l|l|l|l|l|l|l|l|}
\hline Max stress & 350 & 375 & 400 & 410 & 420 & 425 & 430 & 440 & 450 & 460 & 470 \\
[MPa] & & & & & & & & & & & \\
\hline Milled & - & - & RO & RO & RO & RO, RO & X, X & - & - & - & - \\
\hline EDM & RO & RO & RO & RO & RO & - & RO & RO & RO & RO & RO \\
\hline
\end{tabular}

Position tracking at minimum load revealed a significant difference in material behaviour for the two surface conditions as shown in Figure 2. The starting value (zero) originates from a starting load of 0.6 $\mathrm{kN}$, then the averaged position at minimum load over 1000 cycles are plotted for each data point. 


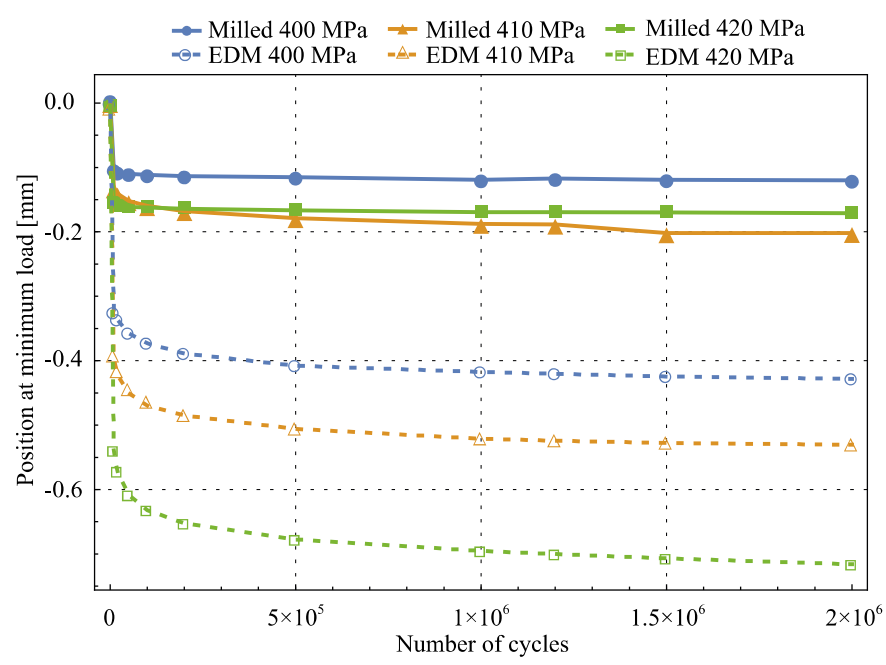

Figure 2: Change in position from $0.6 \mathrm{kN}$ starting load. Position tracking at minimum load for milled and EDM samples at the same loads.

\subsection{Hardness testing and residual stress}

Milling clearly increases the surface hardness as illustrated in Figure 3. Bulk hardness was $\mathrm{HV}_{0.01} 185$ \pm 15 . No changes in hardness could be seen for the EDM sample. The $H V_{0.01}$ hardness for the EDM material was $196 \pm 7$ which is within the range of the bulk hardness.

$$
\text { Bulk minimum }
$$

Figure 3: Micro Vickers indentations for the milled sample illustrated with blue dots, the EDM sample with orange dots, the un-affected bulk as a solid red line, and standard deviation with dashed lines. 
Figure 4 shows the biaxial stresses (solid lines) and FWHM-distribution (dashed lines) measured in three different orientations for both the milled (a) and EDM (b) sample. Post milling, the surface RS are $\sim 500 \mathrm{MPa}$ in tension and converges towards zero at a depth of approximately $30-40 \mu \mathrm{m}$. For the milled material FWHM starts at $1.2^{\circ}$ at the surface and drops to $0.6^{\circ}$ at a depth of $30 \mu \mathrm{m}$, after which the FWHM converges towards the bulk value of $0.35^{\circ}$. The EDM sample showed tensile RS of $200 \mathrm{MPa}$ at the surface which converged close to zero at a depth of $\sim 10 \mu \mathrm{m}$. After which, the mean RS value fluctuates around zero. FWHM at the surface was $0.75^{\circ}$ and converged towards the un-affected bulk value.
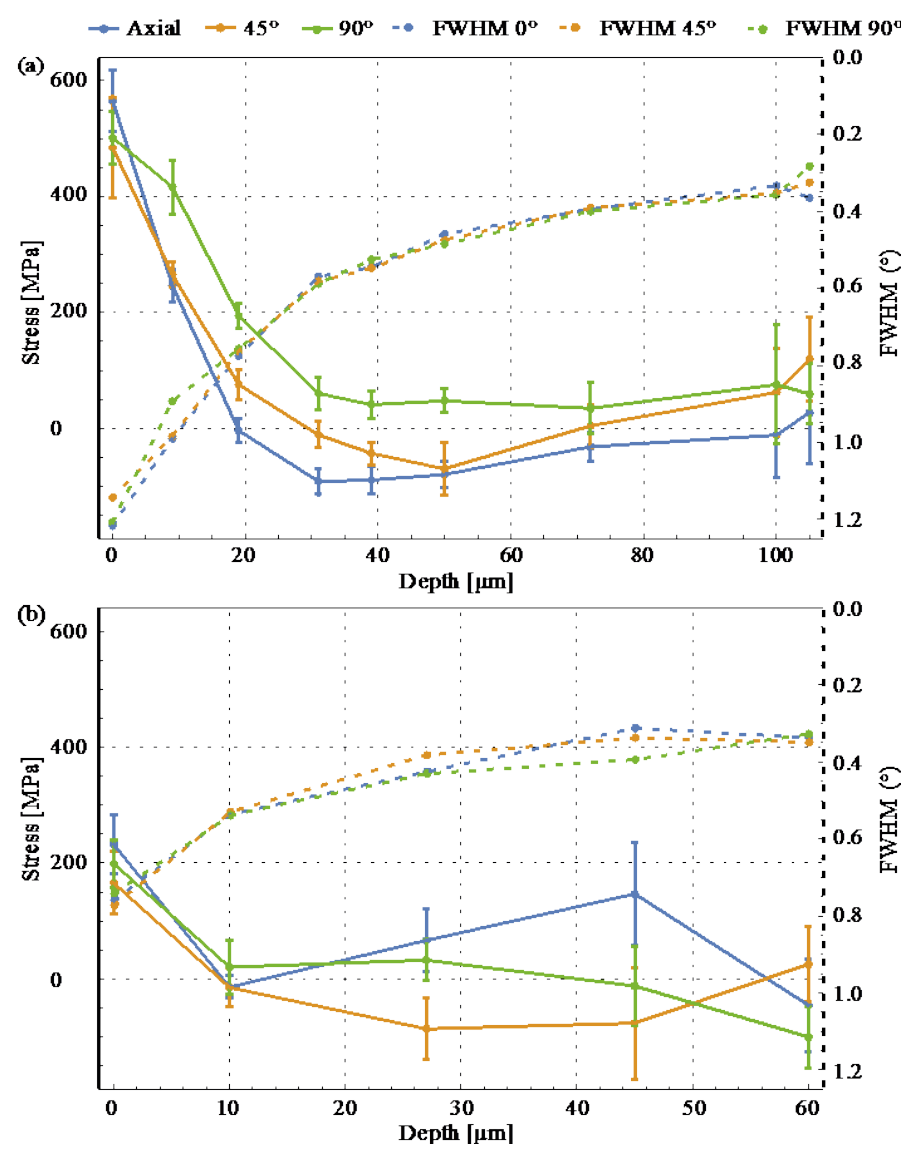

Figure 4: Residual stress and FWHM profile for the (a) milled and (b) EDM sample.

\subsection{Microscopy}

Three distinct zones can often be identified in Figure $5(b)$ after milling: the severe plastically deformed (SPD) zone, the heavily deformed zone, and the affected zone. Nano sized recrystallized grains measuring approximately $40 \times 90-75 \times 150 \mathrm{~nm}$ in the SPD zone are shown in Figure 6 (a). The nano sized 
grains had the longest side parallel to the cutting direction. The heavily deformed zone consists of a mixture of deformation mechanisms in multiple directions and partially evolved nano sized grains as seen in Figure 6 (c). Bending of mechanical twins (MT) is exemplified in Figure 6 (d). The affected zone consists of everything from none to several deformation bands and a speckled pattern, see Figure 6 (b). There is still a rotation of the grains closest to the SPD. A speckled pattern, which is due to variations in elastic and plastic strains, can always be found closest to the heavily deformed zone as well as the extent of the MT.
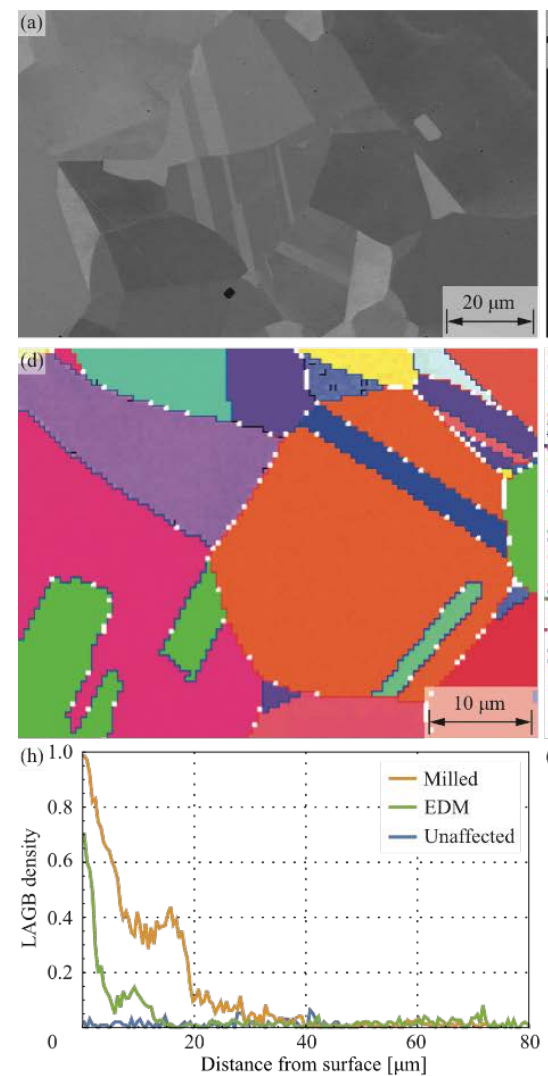
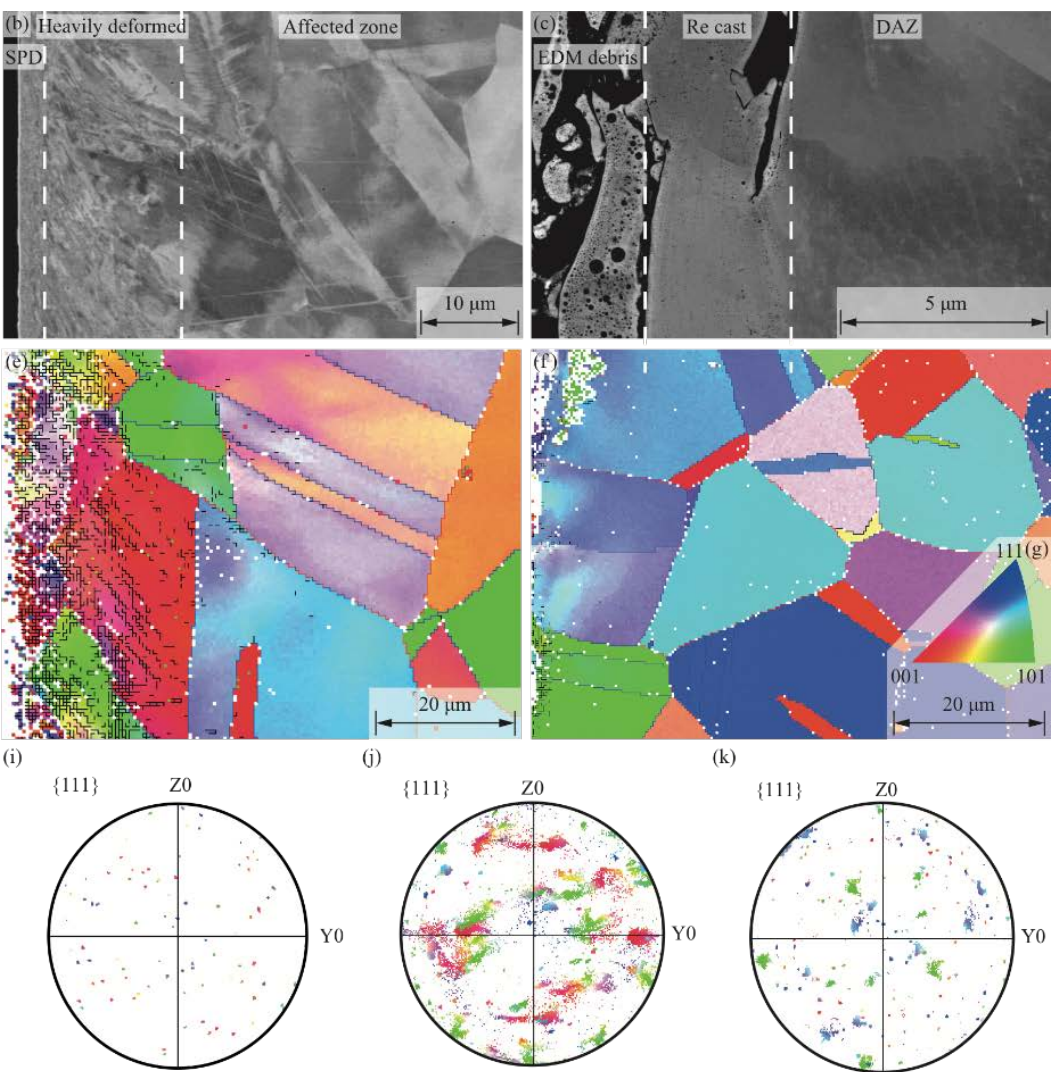

Figure 5: The general microstructure of: (a) unaffected bulk material, (b) the three deformation zones found after milling i.e., affected-, heavily deformed-, and the severe plastic deformation zone, and (c) the typical deformation zones found in the samples after EDM. (d) - (f) Orientation imaging maps of un-affected bulk, milled, and EDM material respectively. (g) IPF colour scheme. (h) LAGB-plot for the un-affected bulk, milled, and EDM material. (i) - (k) Pole figures of un-affected bulk, milled, and EDM material respectively. 

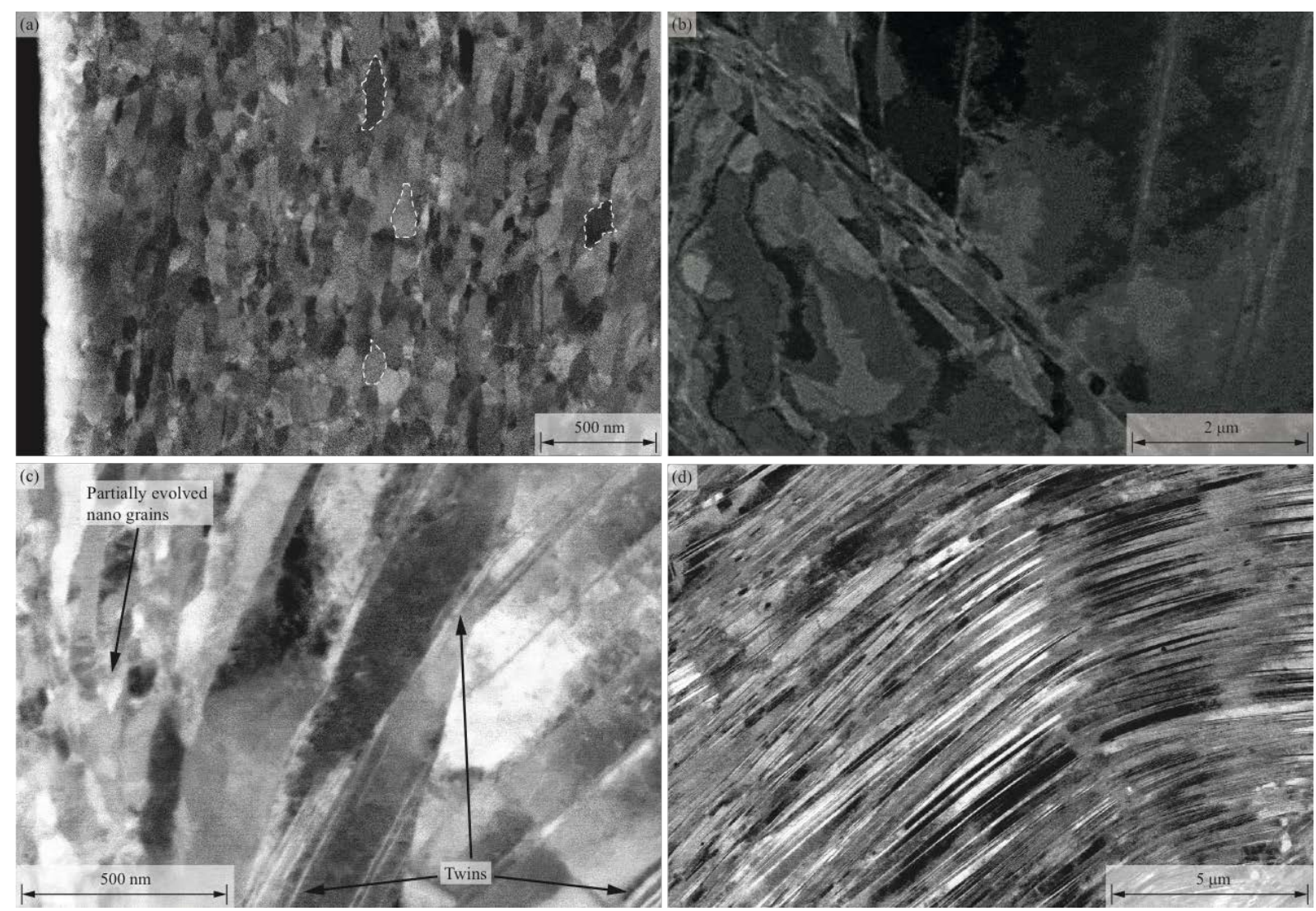

Figure 6: Microstructure images all with the milled surface in the left-hand side showing: (a) The severe plastic deformation zone after milling with recrystallized nano sized grains (some highlighted in white). (b) The affected zone after milling. Speckled pattern and just a few deformation bands located $\sim 20 \mu \mathrm{m}$ from the milled surface. Heavy deformation zone with a (c) mixture of partially evolved nano sized grains and many active deformation systems and (d) highly dense deformation twins.

EDM cuts through the material by partially melting and "flicking" away a fraction of the work piece, the deformation seen is an effect of a melting process. The main microstructural differences between milled and EDM material can be seen when comparing Figure 5 (b) and (c).

The effects of EDM on the surface integrity can be divided into the three different zones: EDM debris, the re cast zone, and the discharge affected zone (DAZ), as depicted in Figure 5 (c). The surface consists of an oxide scale, which varies in thickness, followed by the re cast zone where small black "dots" are 
present. EDS mapping shows an enrichment of copper and zinc in the re cast zone, presented in Figure 7. This makes it possible to conclude that these "dots" are leftovers from the brass wire. DAZ consists of the bulk material, not melted, but affected, by the heat from EDM, in where a pattern similar to a dislocation cell occurs.
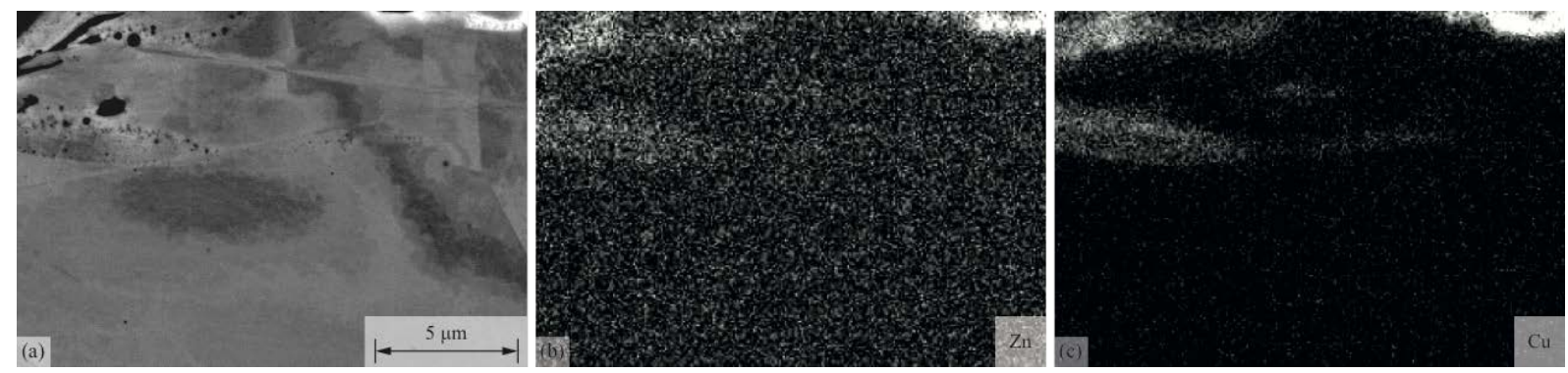

Figure 7: EDS mapping showing concentration of zinc and copper, leftovers from the brass wire, in the regions rich on black dots.

LAGB results are shown in Figure 5 (h). Milling results in a small area with zero solutions in the SPD zone due to nano sized grains and possibly edge effects. This results in a LAGB density of 1 . The LAGB density decreases close to the bulk value during the first $15-20 \mu \mathrm{m}$ from the milled surface. Below this depth, the LAGB density then continues to decrease reaching the same value as the non-deformed material at a depth of $40 \mu \mathrm{m}$.

The LAGB density of the EDM material starts from 0.7 which indicates that the process does not induce a severely plastically deformed surface with the associated strain hardened layer. The re cast material from the work piece and wire causes a steep thermal gradient during cutting, resulting in the observed LAGB density. EDM affects the material to a depth of $15 \mu \mathrm{m}$, with most of the effect at the first five microns from the surface.

\section{Discussion}

The existing research on the effects of EDM on fatigue life has mainly focused on tool steels $[27,28]$, superalloys [29], and Ti alloys [30,31]. 
The fatigue results obtained for the milled surface were as predicted, the material failed at a certain load level. The EDM results, on the other hand, were more unexpected, they were all run-outs.

A fatigue limit does exist for the milled condition even though it was not fully established. This was not the case for the EDM samples, instead they continued plasticising, and none of the samples failed prior the two million cycle failure criterion over the whole stress range. There should be a difference in fatigue strength between the milled and EDM condition. Since surface finish has been found to dramatically change the fatigue strength as reported in [32], where polishing of AISI 316LN was found to be detrimental to the fatigue properties compared to shot peening. The fatigue strength for the milled condition was determined to be approximately $194 \mathrm{MPa}$. There is very little information regarding four-point bending fatigue of stainless steels compared to rotary bending and uniaxial fatigue testing. A summary of existing fatigue strength data at two million cycles for AISI 304, AISI 316, and their derivatives is listed in Table 3 compared for the fatigue test stress amplitude for samples with similar surface integrities. The obtained four-point bending results show greater strength for both the milled and EDM conditions, compared to that found in literature [7]. Due to large scatter, no conclusions can be drawn from three-point bending fatigue data [7-9]. The pure bending results reported for the stronger alloy AISI 316 are significantly lower than ours [32]. Compared to rotary bending $[6,10,14,33]$ our results are roughly $95 \mathrm{MPa}$ lower, which is not so surprising due to the testing method. The results for the milled sample are in line with that of the uniaxial fatigue data for both 304 and 316 alloys [5,34-37]. 
Table 3: Fatigue strength data at two million cycles compared at maximum load for samples with similar surface integrities. Numbers inside brackets () refer to tested material. The results cannot be directly compared due to mean stress effects.

\begin{tabular}{|l|l|l|l|l|l|l|}
\cline { 2 - 7 } \multicolumn{1}{c|}{} & \multicolumn{5}{c|}{ References } \\
\cline { 2 - 7 } \multicolumn{1}{c|}{} & $\begin{array}{l}\text { 4-point } \\
\text { bending }\end{array}$ & Uniaxial & $\begin{array}{l}\text { Rotary } \\
\text { bending }\end{array}$ & 3-point bending & $\begin{array}{l}\text { 4-point } \\
\text { bending }\end{array}$ & Pure bending \\
\hline $\begin{array}{l}\sigma_{\text {amp }} \\
{[\mathrm{MPa}]}\end{array}$ & 194 & $180(304 \mathrm{~L})[34]$ & $233(304)[10]$ & $100(304)[9]$ & $115(316 \mathrm{~L})[7]$ & $220(316)[32]$ \\
& & $280(304)[35]$ & $262(316)[10]$ & $315(304)[8]$ & & \\
Milled & & $185(304 \mathrm{~L})[36]$ & $290(304)[33]$ & $172(316 \mathrm{~L})[7]$ & & \\
& & $370(316)[37]$ & $290(304)[14]$ & & & \\
\hline EDM & $>212$ & $240(316)[5]$ & $366(316 \mathrm{~L})[6]$ & & & \\
& RO & & & & & \\
\hline
\end{tabular}

Three and four-point bend fatigue testing were conducted with electro-polished and ground notched 316L samples [7]. AISI 304 being the low-grade alloy when compared to AISI 316 still show similar fatigue strength when comparing our milled condition specimens with the ground specimens in [7]. This is not the case when comparing our EDM condition specimens with the electro-polished specimens in [7], even though the surface integrity of the two are fairly similar, the EDM samples never fractured (all were run-outs). The fatigue results cannot be directly compared due to mean stress effects.

Surface integrity is mainly tested during four-point bending fatigue. This is why a milled sample can be treated as if the entire sample has been plastically deformed due to milling, EDM samples can instead be treated as un-affected bulk material compared to uniaxial testing. The accumulation rate of inelastic deformation in the EDM sample was likely too low in order to reach the strain limit needed to induce a surface crack and final fracture. For the milled samples the accumulation rate of inelastic deformation was sufficient enough to produce the dislocation density needed to induce a surface crack.

The displacement curves in Figure 2 for the EDM conditions show that the curves decline over the whole testing cycle which is likely due to ratcheting, no decline can be detected for the milled samples. A change in material response was observed using position tracking, as shown in Figure 2. At one 
hundred thousand cycles the milled samples reach a kind of "steady state" remaining to the end compared to the EDM samples which continuously declined. Hysteresis loops for the two conditions at same load level in Figure 8 revealed that ratcheting effects are greater in the EDM sample than the milled. Ratcheting in austenitic stainless steels is common during uniaxial cyclic loading when the nominal stress level is $\neq$ zero $[11-13,38]$. The ratcheting effect makes fatigue strength evaluation quite tricky and is often disregarded. Even though four-point bending fatigue is not the most suitable way to test AISI 304 due to the amount of ratcheting seen in Figure 8 , it is very good when the surface condition/integrity effects are of interest.

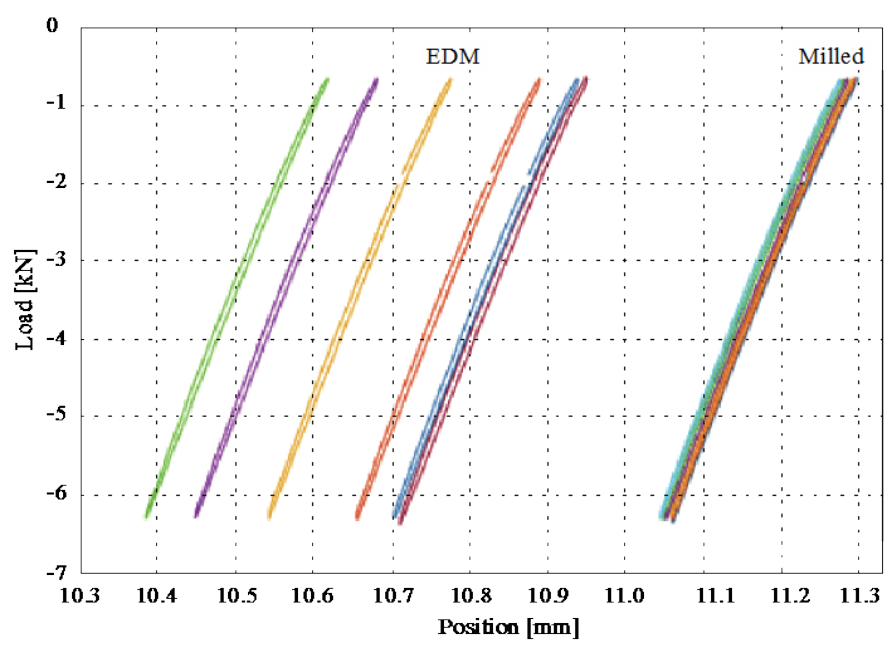

Figure 8: Hysteresis loops for cycle number 30,100,1000,10000, 100000 and 1000000 at $420 \mathrm{MPa}$ load for milled and EDM samples. With increasingly larger cycle number, the hysteresis loop has shifted to the left.

\section{Microscopy}

The microscopy investigation was performed prior to the four-point bending fatigue testing. The main microstructural results are presented in Figures 5 and 6 . In Figure 5 the general microstructure of unaffected bulk, milled, and EDM material is shown in (a) - (c) respectively. Orientation imaging maps of un-affected bulk, milled, and EDM material is shown in (d) - (f) together with an IPF colour scheme in (g) as well as pole figures of un-affected bulk, milled, and EDM material respectively in (i) - (k). A LAGB- 
plot for the un-affected bulk, milled, and EDM material is presented in (h). Figure 6 gives a closer view of the different deformation mechanisms present in the milled samples e.g., recrystallized nano sized grains, deformation bands, and MT.

Coolant was used during milling, resulting in a thin oxide layer on the sample surface. The oxide layer was approximately $1 \mu \mathrm{m}$ thick. Followed by recrystallized nano sized grains in the SPD shown in Figure 6 (a) and (c). In references [8,39-41] it is shown that multiple slip band and nano sized twins in several activated slip systems is caused by machining, forming a grid of high dislocation density walls, from where the recrystallized nano sized grains evolve due to the cutting tool heat generation. In the SPD the LAGB is $\sim 1$, due to few indexed points.

In the heavily deformed zone, multidirectional deformation mechanisms are present. Mechanical twins, shear bands, and slip bands have all been pointed out in the literature to be the main active deformation systems [8,39-44]. The bent MT in Figure 6 (d) are caused by the strong shearing of the work piece induced during milling. MT induced in the stress field will bend as a result of the step strain gradient at the shear band [18]. The heavily deformed area shows a high LAGB density, and high indexation, in contrary to the SPD. LAGB are illustrated with black lines in Figure 5 (e), some are short and some are continuous band. In order to establish if these bands are twins or slip bands a higher resolution is needed than that of the SEM. TEM investigations [8,39-41] on MT in austenitic stainless steels have shown that the twin bands are built up by twining lamellas $10-30 \mathrm{~nm}$ in width with and similar spacing between them. This being the reason for why the EBSD mappings could not fully prove the existence of twins. The in-depth $\mathrm{ECCl}$ investigations, show that the majority of deformations bands observed were actually MT bands. Pole figures of the affected, and heavily deformed areas, displays a clear shearing of the grains with an increasing shearing towards the surface. Mostly scattered twin lamella bands and lattice distortion is seen in the affected zone. The lattice distortion is induced by the surface shearing, which contributes to the speckled pattern seen with $\mathrm{ECCl}$ in Figure 6 (b). There is a good agreement in the affected depth seen with LAGB density plot and the ECCI. 
EDM debris on the EDM sample surface has a thickness ranging between $0-20 \mu \mathrm{m}$ and contains large voids. Spallation is the reason for the zero measurement value. Below the debris is what we refer to as the "re cast" layer as presented in Figure 5 (c). The black "dots" in the re cast layer were found to be enriched with copper and zinc originating from the brass wire used for the EDM process, as well as re-melted material emanating from the work piece. Beneath the re cast layer is the DAZ, DAZ is an effect of the temperature gradient occurring in the work piece during cutting. EDS mapping and line scans were conducted, in order to identify the source of the speckled pattern shown in the DAZ. However, no changes in chemical composition in the DAZ could be seen. Therefore, the speckled pattern seen using ECCl is not due to chemical changes. The differences in LAGB density shown in Figure $5(h)$, suggests that the speckled pattern is due to crystallographic changes, most likely in form of dislocation structures or density. This is supported by the pole figure in Figure $5(\mathrm{k})$ where the grains closest to the surface are illustrated as clusters and not as the single points seen in the un-affected bulk pole figure, Figure 5 (i). The speckled pattern observed with $\mathrm{ECCl}$ are most likely dislocation cells $[8,39,42]$. From the LAGB density, the thickness of the DAZ is approximately $15 \mu \mathrm{m}$ which is the same depth as seen with the ECCl. The DAZ, having a thickness of approximately $15 \mu \mathrm{m}$, gradually changes into un-affected material.

\section{Hardness and residual stress profiles}

Micro Vickers indentations of the milled sample showed that the milled surface and sub-surface were strain hardened. The effect of strain hardening is illustrated in Figure 4, as the bulk value of $185 \pm 15$ $\mathrm{HV}_{0.01}$ increases to approximately $350 \mathrm{HV}_{0.01}$ at the milled surface. This hardness increase is well in line with values reported for $316 \mathrm{~L}[7,45]$. The EDM sample did not show any evident hardening effects with the value of $196 \pm 7$ which is similar to the bulk hardness. Indentations must be placed far enough away from the edge to avoid edge effects. Therefore, the values obtained closest to the edge should be used with caution. The milled samples were expected to give an increase in fatigue strength due to strain hardening compared to the EDM samples. Unsuspectingly, it was the opposite, the EDM samples were 
all RO for our stress range and the milled samples showed a fatigue strength approximately at $194 \mathrm{MPa}$ at our failure criterion as presented in Table 2.

Tensile RS in the surface region are considered detrimental to the fatigue life. Austenitic stainless steels are difficult to machine without generating tensile RS [46]. RS in the milled sample shows a drop from $\sim+500 \mathrm{MPa}$ to approximately zero stresses at $30 \mu \mathrm{m}$. After which the stresses remain close to zero for the whole measured depth. Similar values have been reported in $[47,48]$. In parallel with the change in RS, we see a similar drop in FWHM showing that the dislocation density decreases, resulting in a less strained material. The drop in both RS and FWHM for the milled sample is presented in Figure 3 (a). Less can be said about in change in RS in the EDM sample due to large error bars, seen in Figure 3 (b). Similar issues for RS measurements using X-ray diffraction on AISI 304 has been reported in [49]. Due to the re cast layer both the RS and the FWHM values at the surface should not be treated as absolute. The high tensile RS in the milled sample are in the vicinity of the tensile strength for AISI 304. The high tensile RS and the highly strained surface layer in the milled sample are the reason for why a fatigue strength can be observed. It is problematic to establish a fatigue strength using four-point bending for the EDM sample due to lack of RS and a strained surface which result in a very ductile material response.

This study shows that all techniques used revealed approximately the same affected depth for both the milled and EDM sample. The techniques complement each other, resulting in a better understanding of the materials state post milling and prior the fatigue testing.

\section{Conclusions}

Two different surface conditions, were obtained by milling and EDM, of AISI 304 are fatigue tested and characterised. Surface integrity quantification was done using SEM techniques such as ECCI, EBSD, and EDS. Four-point bending fatigue was used to determine the fatigue performance of the machined surfaces. The post milling deformation depth was approximately $30-40 \mu \mathrm{m}$, which is $<0.4 \%$ of the total sample height. As a consequence, this highly strained region changes the fatigue behaviour. 
- The milled samples exhibit a traditional well established fatigue behaviour, whereas the EDM samples did not fractured.

- Due to the ratcheting effect observed in AISI 304, determining the fatigue strength by using four-point bending fatigue does not seem to be a suitable testing method for EDM condition.

- LAGB density can be used to quantitatively measure plastic deformation.

- Grain shearing and subsequent grain rotation when milling results in bent mechanical twins beneath the surface.

- Mechanical twins and deformation bands form cell structures at the cutting surface, from where nano sized grains evolve due to the heat of the operation.

\section{Acknowledge}

The authors would like to acknowledge the Swedish Government Strategic Research Area in Materials Science on Functional Materials at Linköping University (Faculty Grant SFO-Mat-LiU\#2009-00971) for financial support. A special thanks to Senior Prof. Sten Johansson for SEM assistance and Sandvik Materials Technology for providing the material.

\section{References}

[1] A. Maurotto, D. Tsivoulas, M.G. Burke, Surface Integrity in Dry Milling of 304L Steel: A Parametric Study, Procedia CIRP. 13 (2014) 156-162. doi:10.1016/j.procir.2014.04.027.

[2] V. Chomienne, C. Verdu, J. Rech, F. Valiorgue, Influence of Surface Integrity of 15-5PH on the Fatigue Life, Procedia Eng. 66 (2013) 274-281. doi:10.1016/j.proeng.2013.12.082.

[3] S.G. Acharyya, A. Khandelwal, V. Kain, A. Kumar, I. Samajdar, Surface working of 304L stainless steel: Impact on microstructure, electrochemical behavior and SCC resistance, Mater. Charact. 72 (2012) 68-76. doi:10.1016/j.matchar.2012.07.008.

[4] S. Ghosh, V. Kain, Microstructural changes in AISI 304L stainless steel due to surface machining: Effect on its susceptibility to chloride stress corrosion cracking, J. Nucl. Mater. 403 
(2010) 62-67. doi:10.1016/j.jnucmat.2010.05.028.

[5] M. Kamaya, M. Kawakubo, Mean stress effect on fatigue strength of stainless steel, Int. J. Fatigue. 74 (2015) 20-29. doi:10.1016/j.ijfatigue.2014.12.006.

[6] L. Ceschini, G. Minak, Fatigue behaviour of low temperature carburised AISI 316L austenitic stainless steel, Surf. Coatings Technol. 202 (2008) 1778-1784. doi:10.1016/j.surfcoat.2007.07.066.

[7] A. Laamouri, H. Sidhom, C. Braham, Evaluation of residual stress relaxation and its effect on fatigue strength of AISI 316L stainless steel ground surfaces: Experimental and numerical approaches, Int. J. Fatigue. 48 (2013) 109-121. doi:10.1016/j.ijfatigue.2012.10.008.

[8] C. Ye, A. Telang, A.S. Gill, S. Suslov, Y. Idell, K. Zweiacker, J.M.K. Wiezorek, Z. Zhou, D. Qian, S.R. Mannava, V.K. Vasudevan, Gradient nanostructure and residual stresses induced by Ultrasonic Nano-crystal Surface Modification in 304 austenitic stainless steel for high strength and high ductility, Mater. Sci. Eng. A. 613 (2014) 274-288. doi:10.1016/j.msea.2014.06.114.

[9] N. Ben Fredj, H. Sidhom, Effects of the cryogenic cooling on the fatigue strength of the AISI 304 stainless steel ground components, Cryogenics (Guildf). 46 (2006) 439-448. doi:10.1016/j.cryogenics.2006.01.015.

[10] J. Muñoz-Cubillos, J.J. Coronado, S.A. Rodríguez, Deep rolling effect on fatigue behavior of austenitic stainless steels, Int. J. Fatigue. 95 (2017) 120-131. doi:10.1016/j.ijfatigue.2016.10.008.

[11] X. Yuan, S. Fu, D. Yu, X. Chen, Temperature-Dependent Bending Ratcheting Behavior of a 316LN Stainless Steel, Mater. Eng. Performance2. 25 (2016) 274-279. doi:10.1007/s11665015-1839-9.

[12] G. Kang, Y. Liu, Z. Li, Experimental study on ratchetting-fatigue interaction of SS304 stainless steel in uniaxial cyclic stressing, Mater. Sci. Eng. A. 435 (2006) 396-404. doi:10.1016/j.msea.2006.07.006.

[13] S. Date, H. Ishikawa, T. Otani, Effect of ratcheting deformation on fatigue and creep-fatigue 
life of 316FR stainless steel, Nucl. Eng. Des. 238 (2008) 336-346.

doi:10.1016/j.nucengdes.2006.09.009.

[14] M. Nakajima, Y. Nakamura, K. Suzuki, Y. Bai, Y. Uematsu, Effect of solution treatment after nitriding on fatigue properties in type 304 stainless steel, Int. J. Fatigue. 68 (2014) 103-110. doi:10.1016/j.ijfatigue.2014.05.013.

[15] B. Ravi Kumar, S. Sharma, B.P. Kashyap, N. Prabhu, Ultrafine grained microstructure tailoring in austenitic stainless steel for enhanced plasticity, Mater. Des. 68 (2015) 63-71. doi:10.1016/j.matdes.2014.12.014.

[16] D.Y. Jang, T.R. Watkins, K.J. Kozaczek, C.R. Hubbard, O.B. Cavin, Surface residual stresses in machined austenitic stainless steel, Wear. 194 (1996) 168-173. doi:10.1016/00431648(95)06838-4.

[17] X. Wu, X. Pan, J.C. Mabon, M. Li, J.F. Stubbins, An EBSD investigation on flow localization and microstructure evolution of 316L stainless steel for Gen IV reactor applications, J. Nucl. Mater. 371 (2007) 90-97. doi:10.1016/j.jnucmat.2007.05.028.

[18] Q. Xue, J.F. Bingert, B.L. Henrie, G.T. Gray, EBSD characterization of dynamic shear band regions in pre-shocked and as-received 304 stainless steels, Mater. Sci. Eng. A. 473 (2008) 279-289. doi:10.1016/j.msea.2007.04.048.

[19] R. M'Saoubi, L. Ryde, Application of the EBSD technique for the characterisation of deformation zones in metal cutting, Mater. Sci. Eng. A. 405 (2005) 339-349. doi:10.1016/j.msea.2005.06.002.

[20] J. Nellessen, S. Sandlöbes, D. Raabe, Effects of strain amplitude, cycle number and orientation on low cycle fatigue microstructures in austenitic stainless steel studied by electron channelling contrast imaging, Acta Mater. 87 (2015) 86-99. doi:10.1016/j.actamat.2014.12.024.

[21] T. Zhai, Y.G. Xu, J.W. Martin, A.J. Wilkinson, G.A.D. Briggs, Self-aligning four-point bend testing rig and sample geometry effect in four-point bend fatigue, Int. J. Fatigue. 21 (1999) 889-894. 
doi:10.1016/S0142-1123(99)00084-5.

[22] I.C. Noyan, J.B. Cohan, Residual stress - Measurement by Diffraction and Interpretation, 1987.

[23] B. Eigenmann, E. Macherauch, Röntgenographische Untersuchung von Spannungszuständen in Werkstoffen. Teil III. Fortsetzung von Matwiss. und Werkstofftechn. Heft 3/1995, S. 148160 und Heft 4/1995, S. 199-216, Materwiss. Werksttech. 27 (1996) 426-437. doi:10.1002/mawe.19960270907.

[24] R.J. Kamaladasa, Y.N. Picard, Basic Principles and Application of Electron Channeling in a Scanning Electron Microscope for Dislocation Analysis, Microsc. Scince, Technol. Apl. Educ. (2010) 1583-1590.

[25] S. Zaefferer, N.-N. Elhami, Theory and application of electron channelling contrast imaging under controlled diffraction conditions, Acta Mater. 75 (2014) 20-50. doi:10.1016/j.actamat.2014.04.018.

[26] I. Gutierrez-Urrutia, S. Zaefferer, D. Raabe, Electron channeling contrast imaging of twins and dislocations in twinning-induced plasticity steels under controlled diffraction conditions in a scanning electron microscope, Scr. Mater. 61 (2009) 737-740. doi:10.1016/j.scriptamat.2009.06.018.

[27] O.A. Abu Zeid, On the effect of electrodischarge machining parameters on the fatigue life of AISI D6 tool steel, J. Mater. Process. Technol. 68 (1997) 27-32. doi:10.1016/S09240136(96)02523-X.

[28] F. Ghanem, C. Braham, M.E. Fitzpatrick, H. Sidhom, Effect of near-surface residual stress and microstructure modification from machining on the fatigue endurance of a tool steel, J. Mater. Eng. Perform. 11 (2002) 631-639. doi:10.1361/105994902770343629.

[29] D. Trauth, F. Klocke, D. Welling, M. Terhorst, P. Mattfeld, A. Klink, Investigation of the surface integrity and fatigue strength of Inconel 718 after wire EDM and machine hammer peening, Int. J. Mater. Form. 9 (2016) 635-651. doi:10.1007/s12289-015-1249-4.

[30] S.L. Soo, M.T. Antar, D.K. Aspinwall, C. Sage, M. Cuttell, R. Perez, A.J. Winn, The effect of wire 
electrical discharge machining on the fatigue life of Ti-6Al-2Sn-4Zr-6Mo aerospace alloy, Procedia CIRP. 6 (2013) 215-219. doi:10.1016/j.procir.2013.03.043.

[31] F. Klocke, D. Welling, J. Dieckmann, Comparison of grinding and Wire EDM concerning fatigue strength and surface integrity of machined Ti6Al4V components, Procedia Eng. 19 (2011) 184189. doi:10.1016/j.proeng.2011.11.099.

[32] E.R. de los Rios, A. Walley, M.T. Milan, G. Hammersley, Fatigue crack initiation and propagation on shot-peened surfaces in A316 stainless steel, Int. J. Fatigue. 17 (1995) 493499. doi:10.1016/0142-1123(95)00044-T.

[33] K. Suzuki, Y. Nakamura, M. Nakajima, Y. Bai, Y. Uematsu, Improvement of Fatigue Properties by Solution Treatment in Nitrided Type 304 Stainless Steel, Procedia Mater. Sci. 3 (2014) 627633. doi:10.1016/j.mspro.2014.06.104.

[34] L. Vincent, J.-C. Le Roux, S. Taheri, On the high cycle fatigue behavior of a type 304L stainless steel at room temperature, Int. J. Fatigue. 38 (2012) 84-91. doi:10.1016/j.ijfatigue.2011.11.010.

[35] I. Nikitin, M. Besel, Effect of low-frequency on fatigue behaviour of austenitic steel AISI 304 at room temperature and $25^{\circ} \mathrm{C}$, Int. J. Fatigue. 30 (2008) 2044-2049. doi:10.1016/j.ijfatigue.2008.02.005.

[36] D. Paquet, J. Lanteigne, M. Bernard, C. Baillargeon, Characterizing the effect of residual stresses on high cycle fatigue (HCF) with induction heating treated stainless steel specimens, Int. J. Fatigue. 59 (2014) 90-101. doi:10.1016/j.ijfatigue.2013.09.011.

[37] X. Xie, D. Ning, J. Sun, Strain-controlled fatigue behavior of cold-drawn type 316 austenitic stainless steel at room temperature, Mater. Charact. 120 (2016) 195-202. doi:10.1016/j.matchar.2016.08.031.

[38] L. Taleb, G. Cailletaud, Cyclic accumulation of the inelastic strain in the 304L SS under stress control at room temperature: Ratcheting or creep?, Int. J. Plast. 27 (2011) 1936-1958. doi:10.1016/j.ijplas.2011.02.001. 
[39] J.Z. Lu, K.Y. Luo, Y.K. Zhang, G.F. Sun, Y.Y. Gu, J.Z. Zhou, X.D. Ren, X.C. Zhang, L.F. Zhang, K.M. Chen, C.Y. Cui, Y.F. Jiang, A.X. Feng, L. Zhang, Grain refinement mechanism of multiple laser shock processing impacts on ANSI 304 stainless steel, Acta Mater. 58 (2010) 5354-5362. doi:10.1016/j.actamat.2010.06.010.

[40] F. Han, G.Y. Lin, Q. Li, R.F. Long, D.S. Peng, Q. Zhou, Influence of Different Deformation on Microstructure and Properties of 304 Austenitic Stainless Steel, Adv. Mater. Res. 500 (2012) 690-695. doi:10.4028/www.scientific.net/AMR.500.690.

[41] H.. Zhang, Z.. Hei, G. Liu, J. Lu, K. Lu, Formation of nanostructured surface layer on AISI 304 stainless steel by means of surface mechanical attrition treatment, Acta Mater. 51 (2003) 1871-1881. doi:10.1016/S1359-6454(02)00594-3.

[42] T. Mayama, K. Sasaki, M. Kuroda, Quantitative evaluations for strain amplitude dependent organization of dislocation structures due to cyclic plasticity in austenitic stainless steel 316L, Acta Mater. 56 (2008) 2735-2743. doi:10.1016/j.actamat.2008.02.005.

[43] E.H. Lee, T.S. Byun, J.D. Hunn, M.H. Yoo, K. Farrell, L.K. Mansur, On the Origin of Deformation Microstructures in Austenitic Stainless Steel : Part I - Microstructures, Acta Mater. 49 (2001) $3277-3287$.

[44] E.H. Lee, T.S. Byun, J.D. Hunn, M.H. Yoo, K. Farrell, L.K. Mansur, on the Origin of Deformation Microstructures in Austenitic Stainless Steel : Part I - Microstructures, Acta Mater. 49 (2001) 3269-3276.

[45] A. Yamamoto, T. Yamada, S. Nakahigashi, L. Liu, M. Terasawa, H. Tsubakino, Effects of surface grinding on hardness distribution and residual stress in low carbon austenitic stainless steel 316L, ISIJ Int. 44 (2004) 1780-1782. doi:10.2355/isijinternational.44.1780.

[46] R. M'Saoubi, J.C. Outeiro, B. Changeux, J.L. Lebrun, A. Morão Dias, Residual stress analysis in orthogonal machining of standard and resulfurized AISI 316L steels, J. Mater. Process.

Technol. 96 (1999) 225-233. doi:10.1016/S0924-0136(99)00359-3.

[47] C. Wiesner, Residual stresses after orthogonal machining of AISI 304: numerical calculation of 
the thermal component and comparison with experimental results, Metall. Trans. A. 23 (1992) 989-996. doi:10.1007/BF02675573.

[48] Y. Matsumoto, F. Hashimoto, G. Lahoti, Surface integrity generated by precision hard turning, CIRP Ann. - Manuf. Technol. 48 (1999) 59-62. doi:10.1016/S0007-8506(07)63131-X.

[49] I. Altenberger, B. Scholtes, U. Martin, H. Oettel, Cyclic deformation and near surface microstructures of shot peened or deep rolled austenitic stainless steel AISI 304, Mater. Sci. Eng. A. 264 (1999) 1-16. doi:10.1016/S0921-5093(98)01121-6. 